\title{
The Sentinel Node with Isolated Breast Tumor Cells or Micrometastases. Benefits and Risks of Axillary Dissection
}

\author{
VILMA MADEKIVI ${ }^{1}$, PIA BOSTRÖM $^{2}$, RITTA AALTONEN $^{3}$, TERO VAHLBERG $^{4}$ and EEVA SALMINEN ${ }^{1}$ \\ ${ }^{1}$ Departments of Oncology and Radiotherapy, ${ }^{2}$ Pathology and \\ ${ }^{3}$ Surgery, Turku University Hospital, University of Turku, Turku, Finland; \\ ${ }^{4}$ Department of Biostatistics, University of Turku, Turku, Finland
}

\begin{abstract}
Background/Aim: Sentinel lymph node (SLN) biopsy has become the standard procedure to identify metastases in axillary nodes in breast cancer. Even after careful SLN examination additional micrometastases and isolated tumor cells (ITCS) are sometimes found, resulting in a need for delayed axillary lymph node dissection (ALND). This study was undertaken to assess prognostic factors identifying additional axillary lymph node (ALN) metastases at delayed ALND. Patients and Methods: To define the impact of late ALND regarding their outcome, 162 breast cancer patients with 169 operated breasts treated between 2010 and 2012 were evaluated, with follow-up through 2016. Data were collected on the patients, histology and biologic profile of the cancer, lymph node involvement, recurrence of breast cancer and adverse effects of ALND. Results: With thorough examination and immunohistochemical stainings twenty-nine of 168 SLN biopsies (28 patients, 17\% of the patients) showed micrometastases or ITC, and a full ALND was performed at a later time. During these ALNDs 13 to 31 lymph nodes were removed. Additional ALN metastases were found in three (10\%) patients. Two (7\%) of the 28 patients with triplenegative cancer deceased of metastatic breast cancer. Three patients $(11 \%)$ reported adverse effects of $A L N D$ requiring physiotherapy due to pain, stiffness, swelling or arm oedema. Tumor factors such as molecular subtype $(p=0.002)$, tumor size $(p=0.004)$, and proliferation index (Ki-67) $(p=0.003)$ correlated with higher numbers of ALN metastases. Conclusion: Since most patients with micrometastases found in the primary operation showed no additional positive lymph nodes, completion ALND may not be required in patients with
\end{abstract}

Correspondence to: Eeva Salminen, Department of Radiotherapy and Oncology, Turku University Hospital, BOP 52, FI 20520 Turku, Finland. Tel: +358 23130438, Fax: +358 23132809, e-mail: eevsal@utu.fi

Key Words: Breast cancer, late axillary dissection, micrometastases. micrometastases or ITCs in the SLN. In our study, the predictive factors for additional ALN metastases were tumur size, molecular subtype and proliferation index. It is conceivable that the features of the primary tumor, rather than the amount of cancer cells in the SLN, might serve to identify patients in whom ALDN can be avoided.

The most important prognostic factor in breast cancer is the presence of lymph node metastases, ascertained by needle biopsies, sentinel lymph node biopsy (SLNB) or axillary lymph node dissection (ALND) (1). SLNB are taken from early-stage breast cancer patients to determine whether the cancer cells have infiltrated the axillary lymph nodes (ALNs) (2). As SLNB involves less invasive surgery, it is associated with fewer and less severe adverse effects compared to ALND (3). Having less lymph nodes removed decreases the risk of post-surgical complications such as lymphoedema.

With more sections of paraffin blocks and immunohistochemical stainings, the probability of detecting a positive lymph node increases (4). A postoperative positive SLN finding may necessitate an additional ALND, in which all lymph nodes under the patient's arm are removed. Nevertheless, the samples taken in this second operation may prove to be benign. Patients with negative SLN can thus avoid ALND (5).

The clinical and prognostic significance of a minimal tumor burden in the axilla of breast cancer patients is unclear (6). ITCs are defined as small clusters of tumor cells not greater than $0,2 \mathrm{~mm}$ or clusters of cells not exceeding 200 cells in a single lymph node cross section. Micrometastatic nodal involvement is above $0,2 \mathrm{~mm}$ and up to $2 \mathrm{~mm}$. The most useful distinction remains between metastases of sizes less or more than $2 \mathrm{~mm}(7)$.

When SLNs do not show metastases and ALND is not undertaken, the patient has a $0.3-0.6 \%$ probability of developing ALN metastases within 2-5 years $(8,9)$. However, if micrometastases or ITCs are found in SLNs, the probability of additional ALN metastases is $7.5-15 \%$ (10, 
11). The finding of micrometastases in ALNs indicates worse prognosis than finding of no metastases or solely ITCs (12).

Staging of regional lymph nodes is considered an important step in the selection of breast carcinoma therapy. However, many recent studies have recognized the importance of tumor biology and give rise to further thought as to whether selected SLN-positive patients with limited ALN disease could avoid ALND (13).

The aim of this study was to assess the outcome of late ALND and establish prognostic factors identifying additional lymph node metastases at delayed ALND. Also, the complications of ALND and the outcome of this patient group were examined.

\section{Materials and Methods}

The study was conducted in Turku University Hospital in 20102012. Approximately 500 breast cancer operations are performed yearly in this institute. The relevant data were collected from the archives of the Department of Pathology, Oncology and Surgery.

Records for 162 consecutive patients fulfilling the study criteria included data on 169 operated breasts and 168 SLN investigations. Criteria for inclusion were: metastases in SLNs, divided into macrometastases (dimension $>2 \mathrm{~mm}$ ), micrometastases (dimension $>0.2 \mathrm{~mm}$ ), ITCs (combined dimension $<0.2 \mathrm{~mm}$ ) or positive cytokeratin staining. In addition, patients without SLN metastases were chosen randomly for comparison. Late ALND (in a later separate surgical operation) were performed in 29 cases. The outcome was updated in late 2016 for cancer recurrence and adverse effects related to surgery.

Histological type, size, histopathological grade, Ki-67, presence of DCIS, ER, PR, HER2 receptors, and location of the tumor in the breast were collected. Tumors were classified into luminal A, B, HER2-positive and triple negative tumors. The distinction between luminal A and B types was determined according to the St. Gallen breast cancer conference directives: the cut-off point for Ki-67 was $14 \%$ (14). Triple negative tumors were subdivided into basal types based on cytokeratin CK5/6 and EGFR positivity.

Statistical analyses. Spearman rank-order correlation coefficient was used to calculate the correlation between continuous variables and the number of lymph node metastases. Differences in the number of lymph node metastases between the levels of categorical variables were compared by Mann-Whitney $U$-test or Kruskal-Wallis test with DwassSteel method in pairwise comparisons. Non-parametric methods were used due to skewed distributions. Statistical analyses were made with the SAS System for Windows, release 9.4 (SAS Institute Inc., Cary, NC). $p$-Values less than 0.05 were considered statistically significant.

\section{Results}

Data on 162 patients and 169 operated breasts were collected. The mean age of the patients was $62(\mathrm{SD}=12.2)$ years, range $=28-89$ years. Seventy-six tumors were left-sided and 93 right-sided (55\%); 39 (23\%) tumors were multifocal.

Of the primary breast operations $51(30 \%)$ were resections with SLNB, 66 (39\%) resections with SLNB being followed by immediate ALND, 14 (8\%) ablations with SLNB and 38 (22\%) with SLNB followed by immediate ALND. In addition, one ablation without SLNB was followed by immediate ALND. Both frozen section sampling and paraffin embedded samples were studied at pathology. After the findings had been discussed in a multidisciplinary breast group, late ALND was recommended and performed in 29 cases. The findings are summarized in Table I.

In the entire sample the median (interquartile range) size of the tumor was $18(15) \mathrm{mm}$. There were $135(80 \%)$ ductal invasive cancers, $17(10 \%)$ lobular invasive cancers and 8 (5\%) mere DCIS. Four patients $(2 \%)$ had both lobular and ductal tumors in the same breast. Histological grade was one in 25 (15\%) cases, two in $92(54 \%)$, and three in $52(31 \%)$ cases. One tumor showed invasion of blood vessels $(1 \%)$, sixteen $(9 \%)$ of lymph vessels and two showed $(1 \%)$ perineural invasion.

HER2 oncogene positivity was found in 21 (13\%) cancers. A total of $148(92 \%)$ invasive tumors were ER-positive, 126 (78\%) were PR-positive and 143 (89\%) were both ER- and PRpositive. Ki-67 was $>14 \%$ in $111(67 \%)$ of tumors. Including both invasive and in situ tumors, there were $50(30 \%)$ luminal A, 98 (58\%) luminal B, five (3\%) HER-2 subtype, six (4\%) triple negative cancers and two $(1 \%)$ of basal type.

Frozen section- and paraffin based- SLN findings are presented in Table II. There were no cases in which benign or ITC findings in frozen sections turned out to be macrometastases in the final histopathological assessment. Micrometastases in frozen sections turned out to be macrometastases in four $(20 \%)$ cases.

Malignant cells were observed in the fatty tissue surrounding lymph nodes in three cases, although the SLNs in the frozen section were found to be benign. Paraffin study later confirmed micrometastases in SLNs and the patients in question were treated with late ALND. Similar fatty tissue findings were immediately followed by ALND in two cases concomitant with the primary surgery, since the frozen section also indicated malignancy.

The association between positive SLN finding and number of ALN metastases was statistically significant ( $r=0.63$, $p<0.0001)$. Similarly paraffin block-positive SLNs were associated with ALN metastases $(r=0.78, p<0.0001)$.

The number of ALN metastases was higher in luminal $\mathrm{B}$ cases than in luminal A (median $1.0 v s .0 .5, p=0.002)$. No significant associations of histological grade, age, presence of HER2, DCIS or hormonal receptor status with the number of lymph node metastases were observed.

The size of the tumor (greatest pathological dimension) was significantly associated with the number of lymph node metastases in the axilla (Spearman, $\mathrm{r}=0.22, p=0.004$ ) (Figure 1).

The association between Ki-67 and number of ALN metastases was significant (Spearman, $\mathrm{r}=0.23, p=0.003$ ). The higher the Ki-67, the more metastases were found. 
Table I. Tumor characteristics and findings in surgery and outcome of patients with late axillary dissection (N=28).

\begin{tabular}{|c|c|c|c|c|c|}
\hline $\begin{array}{l}\text { Histology of the } \\
\text { primary tumor, } \\
\text { grade }\end{array}$ & $\begin{array}{l}\text { Tumor } \\
\text { size } \\
(\mathrm{mm})\end{array}$ & $\begin{array}{l}\text { Molecular } \\
\text { subtype }\end{array}$ & $\begin{array}{c}\text { Final diagnosis of } \\
\text { the sentinel lymph } \\
\text { node biopsy }\end{array}$ & $\begin{array}{l}\text { Number of metastases in } \\
\text { axillary dissection/Number } \\
\text { of all dissected lymph nodes }\end{array}$ & $\begin{array}{l}\text { Patient follow-up } \\
\text { information after } \\
\text { four years }\end{array}$ \\
\hline Lobular, 2 & 44 & Luminal A & ITC & $0 / 14$ & No recurrence \\
\hline Ductal, 2 & 27 & Luminal A & ITC & $0 / 10$ & No recurrence \\
\hline Ductal, 2 & 3 & Luminal B & Micrometastasis & $0 / 14$ & No recurrence \\
\hline Lobular, 2 & 17 & Luminal A & Micrometastasis & $0 / 17$ & No recurrence \\
\hline Ductal and Lobular, 1 & 14 & Luminal A & ITC & $0 / 10$ & No recurrence \\
\hline Ductal, 1 & 28 & Luminal, B & Micrometastasis & $0 / 13$ & No recurrence \\
\hline DCIS, 3 & - & - & ITC & $0 / 20$ & No recurrence \\
\hline Ductal, 3 & 17 & Luminal B & Micrometastasis & $0 / 18$ & No recurrence \\
\hline Ductal, 3 & 17 & Luminal B & ITC & $0 / 18$ & No recurrence, AE1 \\
\hline other, 2 & 12 & Luminal B & Micrometastasis & $0 / 30$ & No recurrence \\
\hline Ductal, 3 & 18 & Luminal B & ITC & $0 / 21$ & No recurrence \\
\hline Ductal, 3 & 9 & Luminal B & ITC & $0 / 25$ & No recurrence \\
\hline Ductal, 1 & 7 & Luminal B & Micrometastasis & $0 / 16$ & No recurrence, AE3 \\
\hline Ductal, 1 & 8 & Luminal B & Micrometastasis & $0 / 16$ & No recurrence \\
\hline Ductal, 1 & 8 & Luminal A & Micrometastasis & $0 / 16$ & No recurrence, AE2 \\
\hline Ductal, 2 & 9 & Luminal A & Micrometastasis & $0 / 17$ & No recurrence \\
\hline Ductal, 2 & 23 & Luminal B & Micrometastasis & $0 / 26$ & No recurrence \\
\hline Ductal, 3 & 28 & Triple negative & Micrometastasis and ITC & $0 / 17$ & Distant cancer recurrence, \& \\
\hline Ductal, 3 & 19 & Triple negative & Micrometastasis & $4 / 18$ & Local and distant cancer recurrence, $\&$ \\
\hline Ductal, 1 & 18 & Luminal A & ITC & $0 / 21$ & No recurrence \\
\hline Ductal, 2 & 17 & Luminal A & ITC & $3 / 31$ & No recurrence \\
\hline Ductal, 2 & 11 & Luminal A & Micrometastasis & $0 / 30$ & No recurrence \\
\hline Ductal, 2 & 22 & Luminal B & Micrometastasis & $0 / 13$ & No recurrence \\
\hline Lobular, 2 & 45 & Luminal B & ITC & $0 / 15$ & No recurrence \\
\hline Ductal, 2 & 18 & Luminal A & Micrometastasis & $0 / 16$ & No recurrence \\
\hline Ductal, 2 & 15 & Luminal B & Micrometastasis & $0 / 17$ & No recurrence \\
\hline Ductal, 2 & 22 & HER-2 & ITC & $1 / 19$ & No recurrence \\
\hline Ductal, 3 & 21 & Luminal B & Micrometastasis & $0 / 20$ & No recurrence \\
\hline Ductal, 3 & 17 & Triple negative & Micrometastasis & $0 / 15$ & No recurrence, AE3 \\
\hline
\end{tabular}

DCIS: Ductal carcinoma in situ; \&=died of cancer recurrence; AE: significant adverse effects after axillary dissection.

The results on 29 late ALNDs showed metastases in three cases $(10 \%)$. In these cases the primary tumor was $17-22 \mathrm{~mm}$ in dimension, luminal A, HER-2, or triple negative. Most of the 28 patients (including one with late ALND on both axillas) remained disease-free in follow-up through 2016. Only two patients, both with triple negative breast cancer, had deceased of the disease, one of them being free of metastases in ALND (Table I).

\section{Discussion}

The present findings confirm those of other studies showing that the likelihood of detecting additional LN metastases by late ALND is low. Studies comparing ALND vs. no ALND in early-stage clinically lymph node-negative breast cancer found no improvement in overall survival (15). The Mapping of the Axilla: Radiotherapy or Surgery (AMAROS) trial was presented in 2013 at the European Cancer Congress,
Table II. Sentinel node finding in frozen section and paraffin block analyses.

\begin{tabular}{lcc}
\hline & $\begin{array}{c}\text { Frozen section } \\
\text { N (\%) }\end{array}$ & $\begin{array}{c}\text { Paraffin block } \\
\text { N (\%) }\end{array}$ \\
\hline No metastases & $66(39)$ & $40(24)$ \\
Isolated tumor cells & $18(11)$ & $27(16)$ \\
Micrometastases & $20(12)$ & $39(23)$ \\
Macrometastases & $62(37)$ & $61(36)$ \\
Positive cytokeratin staining & $2(1)$ & $1(1)$ \\
All & $168(100)$ & $168(100)$ \\
\hline
\end{tabular}

One primary operation was done without sentinel node biopsy $n=168$.

suggesting that either axillary radiotherapy or exclusion of further axillary surgery could be a safe alternative to ALND in a highly selected group of patients with limited SLN metastasis without increase in failure rates (16). It is hardly 


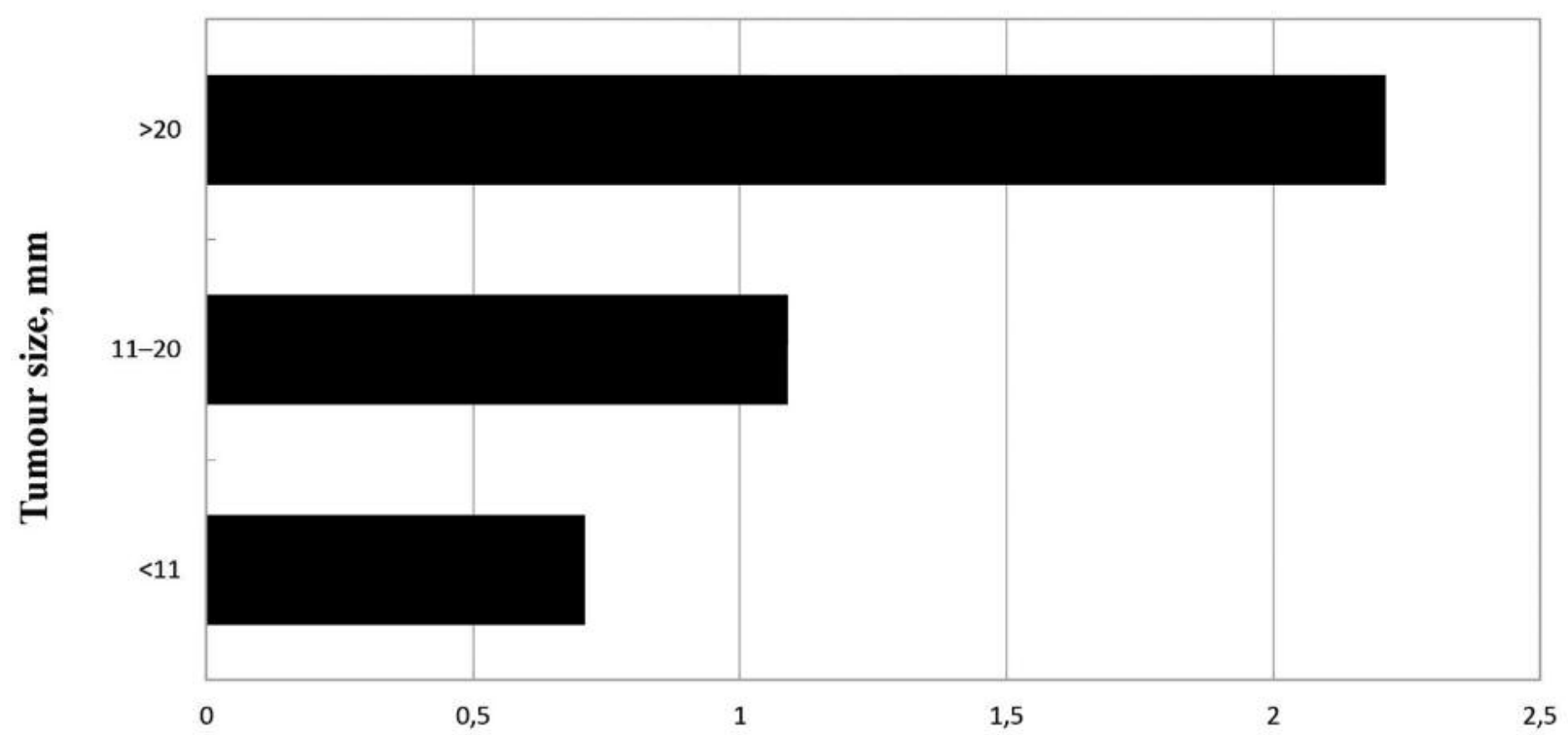

Mean value of number of lymph node metastases

Figure 1. Mean number of axillary lymph node metasteses in tumours of different size.

likely that breast cancer metastases would be found in other ALNs without positive SLNs.

No difference has been reported in the outcome of comparative evaluations in which breast cancer patients were treated based on SLNB or ALND (17). No improvement in disease-free survival was gained with ALND with surgery followed by adjuvant treatment (17-19). The current American Society of Clinical Oncology recommendation avoids ALND if SLNB shows 1-2 lymph node metastases (2).

The risks of late ALND include complications of lymph node removal and the risk of adverse effects due to the operation and anaesthesia. The quality of life of the patient remains better if only SLNB has been performed instead of ALND $(20,21)$. Performance skills improve faster, there is less arm oedema, and patients can return to normal activity earlier than those who undergo ALND (21). Some patients complain of impaired shoulder function and neurologic disturbances (2). Pain is more common after ALND than sentinel node removal (22).

Many centres have developed their own predictive tools for identifying patients with ALN metastases after tumorpositive SLNB in breast cancer. The predictive models for ALN metastases are mostly valid for the centre where they have been developed. For example Tvedskov and associated (23) observed in a comparative assessment of a predictive model in Finnish and Danish patient populations that the Finnish model developed in Helsinki was better indicative in Finnish than in Danish materials.
In our series the decision to proceed to late ALND was made on paraffin block assessment showing micrometastases or ICTs. Only $10 \%$ of late ALND cases were positive for metastases, which is in concert with a previous assessment showing a $7.2-15 \%$ risk of micrometastases or ITC finding being associated with additional ALN metastases $(10,11)$. It may thus be concluded that for most patients late ALND is not needed.

The frozen section was a reliable indicator of metastases; only a few cases of micrometastases turned-out to be macrometastases in final histopathological assessments. The characteristics of tumors in our series were similar to those in other larger reports concerning molecular biology and HER2 positivity $(24,25)$. Tumor size, molecular subtype and proliferation index were predictors of additional LN metastases.

Research in the area of ALN management in breast cancer tends to advocate a more personalised approach based on axillary tumor burden and biology of the cancer (26). The future role of ALND may increasingly be to treat locally persistent or recurrent disease, not to prevent it (27). A conservative approach to ALN is recommended after careful consideration of predictive factors. Tumor size, grade, number of metastatic lymph nodes, and size of the metastatic SLN have been associated with the risk of ALN metastases (28). Also clinically palpable tumors, lymphovascular invasion and growth of the SLN metastases beyond the capsule have predicted ALN metastases (29). 
The present findings may serve as an example of quality control in surgical activity and the process of breast cancer treatment in a hospital. The study provides data valid for consideration of ALND following minimal metastatic findings in frozen sections or final histopathological analyses. Each hospital should periodically evaluate current practices based on their own findings and international evidence based recommendations.

\section{References}

1 Kim H, Cho J, Kwon SY and Kang SH: Biologic subtype is a more important prognostic factor than nodal involvement in patients with stages I and II breast carcinoma. Ann Surg Treat Res 90(1): 1-9, 2016.

2 Lyman GH, Temin S, Edge SB, Newman LA, Turner RR, Weaver DL, Benson AB III, Bosserman LD, Burstein HJ, Cody H III, Hayman J, Perkins CL, Podoloff DA and Giuliano AE: Sentinel lymph node biopsy for patients with early-stage breast cancer: American Society of Clinical Oncology clinical practice guideline update. J Clin Oncol 35(5): 561-564, 2016.

3 Boughey JC, Suman VJ, Mittendorf EA, Ahrendt GM, Wilke LG, Tabak B, Leitch AM, Kuerer HM, Bowling M, FlippoMorton TS, Byrd DR, Ollila DW, Julian TB, McLaughlin SA McCall L, Symmans WF, Le-Petross HT, Haffty BG, Buchholz TA, Nelson Hand Hunt KK, for the Alliance for Clinical Trials in Oncology: Sentinel lymph node surgery after neoadjuvant chemotherapy in patients with node-positive breast cancer: the ACOSOG Z1071 (Alliance) clinical trial. JAMA 310(14): 14551461, 2013.

4 Apple SK: Sentinel Lymph Node in Breast Cancer: Review Article from a Pathologist's Point of View. J Pathol Transl Med 50(2): 83-95, 2016.

5 Zanghì G, Stefano GDI, Caponnetto A, Vecchio R, Lanaia A, La Terra A, Leanza V and Basile F: Breast cancer and sentinel lymph node micrometastases: indications for lymphadenectomy and literature review. G Chir 35(11-12): 260-265, 2014.

6. Hanna MG, Jaffer S, Bleiweiss IJ and Nayak A: Re-evaluating the role of sentinel lymph node biopsy in microinvasive breast carcinoma. Modern Pathology 27: 1489-1498, 2014.

7 de Mascarel I, MacGrogan G, Debled M, Brouste V and Mauriac L: Distinction between isolated tumor cells and micrometastases in breast cancer. Cancer 112(8): 1672-1678, 2008.

8 van der Ploeg IM, Nieweg O E, van Rijk M C, Valdés Olmos R A and Kroon BB: Axillary recurrence after a tumor-negative sentinel node biopsy in breast cancer patients: a systematic review and meta-analysis of the literature. Eur J Surg Oncol 34: 1277-1284, 2008.

9 Bulte CS, van der Heiden-van der Loo M and Hennipman A: Axillary recurrence rate after tumor negative and micrometastatic positive sentinel node procedures in breast cancer patients, a population based multicenter study. Eur J Surg Oncol 35(1): 2531,2009

10 Cserni G, Gregori D, Merletti F, Sapino A, Mano M P, Ponti A, Sandrucci S and Baltás B and Bussolati G: Meta-analysis of nonsentinel node metastases associated with micrometastatic sentinel nodes in breast cancer. Br J Surg 91(10): 1245-1252, 2004.

11 Meretoja TJ, Strien L, Heikkilä PS and Leidenius MH: A simple nomogram to evaluate the risk of nonsentinel node metastases in breast cancer patients with minimal sentinel node involvement. Ann Surg Oncol 19(2): 567-576, 2011.

12 Andersson Y, Frisell J, Sylvan M, de Boniface J and Bergkvist $\mathrm{L}$ : Breast cancer survival in relation to the metastatic tumor burden in axillary lymph nodes. J Clin Oncol 28(17): 28682873, 2010

13 Mayer EL: Breast Cancer Axillary Staging: Much Ado About Micrometastatic Disease. J Clin Oncol 33(10): 1095-1097, 2015.

14 Goldhirsch A, Wood WC, Coates AS, Gelber RD, Thürlimann B and Senn H-J: Strategies for subtypes - dealing with the diversity of breast cancer: highlights of the St Gallen international expert consensus on the primary therapy of early breast cancer 2011. Ann Oncol 22(8): 1736-1747, 2011.

15 Sanghani M, Balk EM and Cady B: Impact of axillary lymph node dissection on breast cancer outcome in clinically node negative patients. Cancer 115(8): 1613-1620, 2009.

16 Qiu SQ, Zeng HC, Zhang F, Chen C, Huang WH, Pleijhuis RG, Wu JD, van Dam GM and Zhang GJ: A nomogram to predict the probability of axillary lymph node metastasis in early breast cancer patients with positive axillary ultrasound. Scientific reports 6: 21196, 2016.

17 Senkus E, Kyriakides S, Penault-Llorca F, Poortmans P, Thompson A, Zackrisson S and Cardoso F: ESMO guidelines working group. Primary breast cancer: ESMO clinical practice guidelines for diagnosis, treatment and follow-up. Ann Oncol 24: vi7-23, 2013.

18 Galimberti V, Cole BF, Zurrida S, Viale G, Luini A, Veronesi P, Baratella P, Chifu C, Sargenti M, Intra M, Gentilini O, Mastropasqua MG, Mazzarol G, Massarut S, Garbay JR, Zgajnar J, Galatius H, Recalcati A, Littlejohn D, Bamert M, Colleoni M, Price KN, Regan MM, Goldhirsch A, Coates AS, Gelber RD and Veronesi U: International breast cancer study group trial 23-01 investigators. Axillary dissection versus no axillary dissection in patients with sentinel-node micrometastases (IBCSG 23-01): a phase 3 randomised controlled trial. The Lancet Oncology 14(4): 297-305, 2013

19 Giuliano AE, Hunt KK, Ballman KV, Beitsch PD, Whitworth PW, Blumencranz PW, Leitch AM, Saha S, McCall LM and Morrow M: Axillary dissection vs. no axillary dissection in women with invasive breast cancer and sentinel node metastasis: a randomized clinical trial. JAMA 305(6): 569-575, 2011

20 Rao R, Euhus D, Mayo HG and Balch C: Axillary node interventions in breast cancer. A systematic review. JAMA 310(13): 1385-1394, 2013.

21 Mansel R, Fallowfield E, Kissin M and Goyal A: Randomized multicenter trial of sentinel node biopsy versus standard axillary treatment in operable breast cancer: the ALMANAC trial. J Natl Cancer Inst 98(9): 599-609, 2006.

22 Mejdahl MK, Andersen KG, Gärtner R, Kroman N and Kehlet $\mathrm{H}$ : Persistent pain and sensory disturbances after treatment for breast cancer: six year nationwide follow-up study. BMJ 346 : f1865, 2013.

23 Tvedskov TF, Meretoja TJ, Jensen MB, Leidenius $M$ and Kroman N: Cross-validation of three predictive tools for nonsentinel node metastases in breast cancer patients with micrometastases or isolated tumor cells in the sentinel node. Eur J Sur Oncol 40(4): 435-441, 2014.

24 Nadji M, Gomez-Fernandez C, Ganjei-Azar P and Morales AR: Immunohistochemistry of estrogen and progesterone receptors reconsidered. Am J Clin Pathol 123(1): 21-27, 2005. 
25 Howlader N, Chen V W, Ries L A, Loch MM, Lee R, DeSantis $\mathrm{C}$, Lin CC, Ruhl J and Cronin KA: Overview of breast cancer collaborative stage data items - their definitions, quality, usage, and clinical implications: a review of SEER data for 2004-2010. Cancer 120: 3771-3780, 2014.

26 Voutsadakis IA and Spadafora S: Axillary lymph node management in breast cancer with positive sentinel lymph node biopsy. World J Clin Oncol 6(1): 1-6, 2015.

27 Ho A and Cody HS: Which patients with sentinel node-positive breast cancer can avoid axillary dissection? Breast Cancer 2013 Educational Book. Am Soc ClinOncol Educ Book 2013: 61-65, 2013.
28 Goyal A, Douglas-Jones A, Newcombe RG and Mansel RE: ALMANAC Trialists Group. Predictors of non-sentinel lymph node metastasis in breast cancer patients. Eur J Cancer 40(11): 1731-1737, 2004.

29 Saidi RF, Dudrick PS, Remine SG and Mittal VK: Nonsentinel lymph node status after positive sentinel lymph node biopsy in early breast cancer. Am Surg 70(2): 101-105, 2004.

Received May 10, 2017

Revised May 25, 2017

Accepted May 26, 2017 